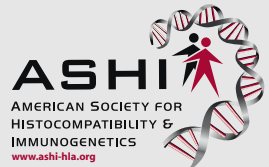

journal homepage: www.elsevier.com/locate/humimm

Rapid Communication

\title{
HLA-E polymorphisms in an Afro-descendant Southern Brazilian population
}

\author{
Luana Carvalho dos Santos, Luciane Viater Tureck, Pryscilla Fanini Wowk, Sibelle Botogosque Mattar, \\ Georgia Fernanda Gelmini, João Carlos Marques Magalhães, Maria da Graça Bicalho, \\ Valéria Maria Munhoz Sperandio Roxo*
}

Laboratory of Immunogenetics and Histocompatibility, Genetics Department, Universidade Federal do Paraná, Curitiba, Brazil

\section{A R T I C L E I N F O}

Article history:

Received 25 April 2012

Accepted 26 October 2012

Available online 5 November 2012

\begin{abstract}
A B S T R A C T
$H L A-E$ is a non-classical I (Ib) gene which has limited polymorphism and low levels of tissue expression. Currently, 11 alleles are described in the literature with only three protein products. In the present study we investigated HLA-E gene variations at exons 2 and 3 and calculated allele, genotype and haplotype frequencies in a sample of 152 individuals who reported themselves as being Afro-descendants and who are voluntary bone marrow donors living in the state of Paraná, Brazil. The most frequent allele in the sample analyzed was the $E^{*} 01: 01$ (59.21\%). The presence of the $E^{*} 01: 04$ allele was not detected suggesting that it has a very low worldwide frequency or that this allele may be an artifact of sequencing. We reported the most frequent alleles found as well as genotypes and haplotypes and compared our results with the few other studies found in the literature. This study is the first to investigate Afro-descendants from the South of Brazil.

(C) 2012 American Society for Histocompatibility and Immunogenetics. Published by Elsevier Inc. All rights
\end{abstract} reserved.

\section{Introduction}

The three non-classical class Ib genes, HLA-E, HLA-F and HLA-G, located in the class I region of the Major Histocompatibility Complex $\left(\mathrm{MHC}^{1}\right)$ in humans can be distinguished from the classical class Ia genes by their low allelic polymorphism, specific expression patterns, peptide binding properties and immune-related functions [1]. The recent description of HLA-E and HLA-G antigens as ligands for distinct killing inhibitory receptors expressed by immunocompetent cells has highlighted the specific role of nonclassical class I molecules in modulating immune responses. In contrast to $H L A-G$, which has a restricted pattern of expression [2], HLA-E is ubiquitously expressed [3].

$H L A-E$ is located between the HLA-C and $-A$ genes [4] and, unlike MHC class Ia, is highly conserved and the biological significance of its genetic polymorphism is uncertain [5]. Currently, 11 alleles are described in the literature: $H L A-E\left(E^{*} 01: 01: 01: 01, E^{*} 01: 01: 01: 02\right.$, $E^{*}$ 01:01:01:03, $\quad E^{*}$ 01:03:01:01, $\quad E^{*}$ 01:03:01:02, $\quad E^{*}$ 01:03:02:01, $E^{*}$ 01:03:02:02, $\left.E^{*} 01: 03: 03, E^{*} 01: 03: 04, E^{*} 01: 03: 05, E^{*} 01: 04\right)$, which

* Corresponding author. Address: Laboratório de Imunogenética e Histocompatibilidade, Departamento de Genética, Universidade Federal do Paraná, R. Cel. Francisco H. dos Santos S/N, Centro Politécnico - Jardim das Américas, CP 19071, CEP 81.530.990, Curitiba, PR, Brazil. Fax: +55 4132662042

E-mail address: valroxo@ufpr.br (V.M.M.S. Roxo).

Abbreviations: ADP, Afro-descendants - Paraná; AEUA, African American-United States; AMOVA, analysis of molecular variance; BRA, Brazilians - São Paulo; CAD, caucasians - Denmark; MHC, major histocompatibility complex; SNP, single nucleotide polymorphism. encode only three protein products (IMGT/HLA Database) [6]. There are three allelic variations which are non-synonymous and correspond to $E^{*} 01: 01, E^{*} 01: 03$ and $E^{*} 01: 04$ [7]. Alleles $H L A-E^{*} 01: 01$ and $H L A-E^{*} 01: 03$ differ only at codon 107 of exon 3; HLA-EG presents codon (GGG) which stands for asparagine whereas HLA-ER has an arginine (AGG) [8]. These two alleles seem to have different levels of expression and HLA-EG molecules are found in a higher concentration in the cell surface as compared to HLA-ER [9]. This difference in expression of the two alleles not only reflects the affinity of HLAE107G for peptides but also the greater stability of the complex on the cell surface. The variation $E^{*} 01: 04$ has two nucleotide substitutions; the first is located at codon 107 which encodes a glycine (GGG) instead of an arginine (AGG). The second at codon 157 which presents a substitution of an arginine for a glycine, differentiates these alleles from the afore mentioned.

The HLA-E molecule shows less variation in its amino acid sequence than other HLA class I molecules [10]. For the stabilization of the molecule on the cell surface, peptides derived from the leader sequence of several HLA class I molecules including HLAA, HLA-B, HLA-C and HLA-G are requested [11]. Evidences suggest that HLA-E molecules can also bind to viral and bacterial peptides [12]. HLA-E has been identified as a ligand for the CD94/NKG2A and CD94/NKG2C receptors expressed in NK cells, which are part of innate immunity [13]. This interaction is dependent on the association of HLA-E with nonamers derived from class I leader peptides and variations in these peptides affect the stability of HLA-E determining whether HLA-E/peptide complexes are stable and can be expressed in the cell surface and can protect this cell 
from NK lysis after being recognized by the CD94/NKG2A receptors [14]. Interestingly, the presence of HLA-E at the cell surface serves as a surrogate marker for the integrity of the key parts of the class I antigen processing pathway. Any interference of processing or of display will render the cell vulnerable to lysis by NK cells [15].

In this study we analyzed polymorphisms in exons 2 and 3 of the HLA-E gene in a sample of Afro-descendants who live in the state of Paraná, in Southern Brazil. The aim of this work was to characterize these gene polymorphisms in our population and to present data which can serve as a basis for future population and association studies. Few population studies have been conducted for $H L A-E$ and in only a limited number of populations. The importance of $H L A-E$ variation to transplant rejection, disease susceptibility and immunity has yet to be explored.

\section{Materials and methods}

\subsection{Study population}

A total of 152 unrelated healthy bone marrow donors were genotyped for HLA-E exons 2 and 3 at the Laboratory of Immunogenetics and Histocompatibility of the Federal University of Paraná, Brazil (LIGH-UFPR). All individuals classified themselves as Afro-Brazilians and were mainly from the capital city of the State of Paraná, Curitiba and from its metropolitan region. Samples were collected from 2007 to 2010. The study was approved by the Ethics Committee of the Hospital das Clínicas of the UFPR (HC-UFPR/CEP-HC no. 037 ext.019/2001-07). All participants signed a free and informed consent form and completed a personal and occupational questionnaire.

\subsection{HLA-E genotyping}

Exons 2 and 3 of the $H L A-E$ gene were amplified by PCR using oligonucleotide primers ( $5^{\prime}$ GGGGTCGGGATGGAAACGGC $3^{\prime}$ ) and (5' GGTTCCGCAGCCTTGGGGTGA $3^{\prime}$ ) for exon 2 and (5' CGGAA CCCGCCCAGACCCTA $3^{\prime}$ ) and (5' TGAGGTCTGTCAGCTGTGGG $3^{\prime}$ ) for exon 3. PCR was performed according to the following conditions: final volume of $50 \mu \mathrm{L}$ containing: $1 \mathrm{X}$ PCR buffer $(70 \mathrm{mM}$ Tris- $\left.\mathrm{HCl} \mathrm{pH} 8.8,20 \mathrm{mM}\left(\mathrm{NH}_{4}\right)_{2} \mathrm{SO}_{4}\right), 1 \mathrm{mM} \mathrm{MgCl}, 0.45 \mathrm{mM}$ of each dNTPs, 20 pMol of each primer, 2 units of Taq DNA polymerase Platinum (Invitrogen, Carlshad, CA) and $30 \mathrm{ng}$ of genomic DNA, resulting in a $985 \mathrm{bp}$ PCR product. The cycle of initial denaturation was $94{ }^{\circ} \mathrm{C}$ for $3 \mathrm{~min}$ followed by 35 cycles of $94{ }^{\circ} \mathrm{C}$ for $30 \mathrm{~s}, 68^{\circ} \mathrm{C}$ for $30 \mathrm{~s}$ and $72{ }^{\circ} \mathrm{C}$ for $60 \mathrm{~s}$. The final extension step was $72{ }^{\circ} \mathrm{C}$ for $4 \mathrm{~min}$ (GeneAmp PCR System 9700) $12 \mu \mathrm{L}$ of PCR product were then purified, using 20 units of Exonuclease (EXOI) (United States Biochemical - USB, Staufen, Germany), 4 units of shrimp alkaline phosphatase (SAP) (USB) and $2 \times$ SAP Buffer (USB). The purified PCR product of exons 2 and 3 of the HLA-E gene were sequenced using an ABI Prism Big Dye Terminator $\mathrm{Cy}-$ cle Sequencing Kit version 3.3 (Applied Biosystems, CA, USA) and ABI Primers 3130 Genetic Analyzer (Applied Biosystems, CA, USA). The primers used in the direct DNA sequencing reaction were the same as for PCR amplification (forward and reverse). All the sequences obtained from each sample were aligned with the genomic sequences of the official alleles (recognized by the WHO and the International Immunogenetics Information System - IMGT) and each single nucleotide polymorphism (SNP) detected was individually noted.

\subsection{Statistical analysis}

Allele and genotype frequencies were determined by direct counting. Adherences of genotype proportions to expectations un- der Hardy-Weinberg equilibrium were tested by the exact test of Guo and Thompson using the GENEPOP 3.4 software. Haplotype frequencies and LD values were calculated with the software package Arlequin version 3.1 [16]. Genetic similarity between our sample and different ethnic groups were calculated with program Biostat version 5.0 and the analysis of molecular variance (AMOVA) used Arlequin for values of FST. Departure from selective neutrality was evaluated by three different methods: the Ewens-Watterson test implemented by Slatkin that permits to test alternative hypotheses of either directional or balancing selection; the Tajima's $D$ test, which examines the relationship between the number of segregating sites and nucleotide diversity by comparing the sequence diversity statistics $\theta \mathrm{w}$ and $\pi$ and the Fu and Li test which included the synonymous and non-synonymous nucleotide substitutions. All tests were carried out using the ARLEQUIN version 3.1 program.

\section{Results}

Allele, genotype and haplotype frequencies found in the sample population studied are shown in Table 1. $E^{*} 01: 03: 02$ and $E^{*}$ 01:03:04 alleles were considered together as exon 8 was not analyzed. The $E^{*} 01: 04$ allele was not found in our sample. Thus, it was not possible to confirm its existence, corroborating the hypothesis that this allele may be an artifact of sequencing. On the other hand the allele with the highest frequency was $E^{*} 01: 01$ (59.1\%). All genotype frequencies were in Hardy-Weinberg equilibrium, with $P=0.3389$.

We report only the haplotypes that were found in a frequency superior to $0.04 \%$. They were used for the analysis of molecular variance in order to compare genetic diversity between the different populations studied. According to the results obtained by AMOVA, the degree of differentiation between our sample and Euro-Caucasians studied by Antoun et al. [17], was $3.874 \%, P=0.035$. In turn, the difference obtained between our population and Afro-Americans reported by Grimsley and Ober [18] was of 5.368\% with $P=0.069$. These data show that our sample is more similar to the Euro-Caucasians due to the European migration to our country. Neutrality tests did not present significant results when exons were examined together or separately.

\section{Discussion}

The analysis of genetic polymorphisms in exons 2 and 3 of the $H L A-E$ gene in a sample composed by self-reported Afrodescendants living in the southern state of Paraná, Brazil allows us to infer that the frequencies of the $E^{*} 01: 01$ and $E^{*} 01: 03$ alleles are similar, reinforcing the possibility of balanced selection. The $H L A-E^{*} 01: 04$ allele was not found in our sample.

The genotype frequencies of SNP'S 1114 and 1446 were compared between our sample and results found by Antoun et al. in Euro-Caucasian, African Caribbean and Asian populations (data not shown) [17]. Differences in the genotype SNPs frequencies were not significant when our sample was compared with EuroCaucasians and African Caribbeans. In turn, statistically significant differences were found between our population and Asians analyzed by the same authors. These results are expected due to the ethnic composition of our sample which was formed by Africans who came to our country as working force and admixed with Euro-Caucasians and the native indigenous populations.

We compared the similarity of frequencies of alleles $E^{*} 01: 01$; $E^{*}$ 01:03:01, $E^{*}$ 01:03:03 and $E^{*}$ 01:03:02:01 between our sample and healthy bone marrow donors from the state of São Paulo, Brazil, Caucasians of Denmark and African Americans of the United States (Table 2) [18,19]. Interestingly our sample differed signifi- 
Table 1

HLA-E alleles, genotypes, haplotypes frequencies in Afro-descendants from Paraná.

\begin{tabular}{|c|c|c|c|c|c|c|}
\hline \multicolumn{4}{|l|}{ Alleles } & $n=304$ & $\%$ & \\
\hline \multicolumn{4}{|l|}{$\mathrm{E}^{*} 01: 01$} & 180 & 59.1 & \\
\hline \multicolumn{4}{|c|}{$E^{*} 01: 03: 013$} & 38 & 12.5 & \\
\hline \multicolumn{4}{|c|}{$E^{*} 01: 03: 02 / 01: 03: 04$} & 76 & 25 & \\
\hline \multicolumn{4}{|c|}{$E^{*} 01: 03: 03$} & 10 & 3.4 & \\
\hline \multicolumn{4}{|l|}{ Genotypes } & $n=152$ & $\%$ & \\
\hline \multicolumn{4}{|c|}{$E^{*} 01: 01,01: 01$} & 56 & 36.84 & \\
\hline \multicolumn{4}{|c|}{$E^{*} 01: 01,01: 03: 01$} & 26 & 17.10 & \\
\hline \multicolumn{4}{|c|}{$E^{*} 01: 01,01: 03: 02 / 01: 03: 04$} & 42 & 27.63 & \\
\hline \multicolumn{4}{|c|}{$E^{*} 01: 03: 01,01: 03: 01$} & 5 & 3.29 & \\
\hline \multicolumn{4}{|c|}{$E^{*} 01: 03: 01,01: 03: 02 / 01: 03: 04$} & 12 & 7.89 & \\
\hline \multicolumn{4}{|c|}{$\mathrm{E}^{*} 01: 03: 02 / 01: 03: 04,01: 03: 02 / 01: 03: 04$} & 8 & 5.26 & \\
\hline \multicolumn{4}{|c|}{$\mathrm{E}^{*} 01: 03: 02 / 01: 03: 04,01: 03: 03$} & 3 & 1.97 & \\
\hline Haplotypes & Obs. $\mathrm{n}$ & $\%$ & +1114 & +1446 & +1577 & Related alleles \\
\hline \multicolumn{3}{|l|}{ IMGT/HLA } & 77 & 107 & 150 & \\
\hline 1 & 92 & 30.26 & $\mathrm{C}$ & A & $\mathrm{C}$ & $E^{*} 01: 01$ or $01: 03: 01$ \\
\hline 2 & 85 & 27.96 & $\mathrm{C}$ & G & C & $E^{*} 01: 03$ or $01: 03: 01$ \\
\hline 3 & 83 & 27.3 & $\mathrm{~T}$ & A & $\mathrm{C}$ & $E^{*} 01: 01,01: 03: 02$ or $01: 03: 04$ \\
\hline 4 & 23 & 7.56 & $\mathrm{~T}$ & G & C & $E^{*} 01: 03,01: 03: 02$ or $01: 03: 04$ \\
\hline 5 & 15 & 4.93 & C & G & $\mathrm{T}$ & $E^{*} 01: 03: 01$ or $01: 03: 03$ \\
\hline
\end{tabular}

Table 2

Allele and genotype frequencies comparisons between four different ethnic groups.

\begin{tabular}{|c|c|c|c|c|c|c|c|c|}
\hline \multirow[b]{2}{*}{ Alleles } & \multicolumn{2}{|l|}{ ADP } & \multicolumn{2}{|l|}{ BRA } & \multicolumn{2}{|l|}{ CAD } & \multicolumn{2}{|c|}{ AEUA } \\
\hline & $n$ & Freq.\% & $n$ & Freq.\% & $n$ & Freq.\% & $n$ & Freq.\% \\
\hline $\mathrm{E}^{*} 01: 01$ & 180 & 59.21 & 65 & 62.50 & 170 & 56 & 96 & 89 \\
\hline $\mathrm{E}^{*} 01: 03: 01$ & 38 & 12.5 & 10 & 9.13 & 29 & 09 & 10 & 8,84 \\
\hline$E^{*} 01: 03: 03$ & 10 & 3.28 & 0.0 & 0.0 & 101 & 35 & 02 & 2,16 \\
\hline \multirow[t]{2}{*}{$E^{*} 01: 03: 02: 01$ or $01: 03: 04$} & 76 & 25.00 & 25 & 24.52 & & & & \\
\hline & \multicolumn{2}{|l|}{ ADP } & \multicolumn{2}{|c|}{ AEUA } & \multicolumn{2}{|l|}{$\mathrm{HI}$} & \multicolumn{2}{|l|}{$\mathrm{CH}$} \\
\hline Genotype & $n$ & Freq.\% & $n$ & Freq.\% & $n$ & Freq.\% & $n$ & Freq.\% \\
\hline$E^{*} 01: 01,01: 01$ & 56 & 37 & 24 & 36 & 14 & 30 & 1 & 4 \\
\hline$E^{*} 01: 01,01: 03$ & 68 & 45 & 10 & 45 & 26 & 54 & 10 & 40 \\
\hline$E^{*} 01: 03,01: 03$ & 28 & 18 & 13 & 19 & 8 & 16 & 14 & 56 \\
\hline
\end{tabular}

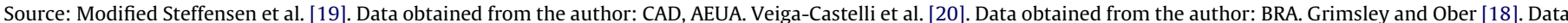

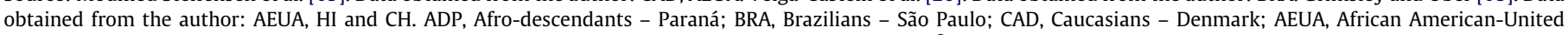

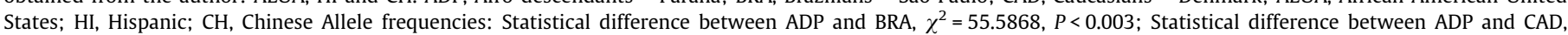

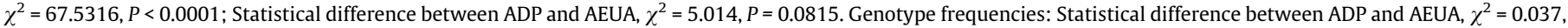
$P=0.9816$, Statistical difference between ADP and HI, $\chi^{2}=1.367, P=0.50491$ Statistical difference between ADP and $C H, \chi^{2}=20.077, P<0.0001$.

cantly from the sample of individuals from São Paulo, studied by Veiga-Castelli et al. [20]. This reflects a different population composition between both samples. Our sample also differed significantly from the Caucasian sample of Denmark and was similar to the African American sample studied by Stefensen et al. [19].

Our allele frequencies were also compared with three different Amerindian samples from Mexico, Colombia and Chile [21]. Significant differences were observed in all instances which can be explained by the fact that we are comparing an Afro-descendant sample with the indigenous Americans. Even if our sample was expected to have an Ameridian component due to admixture, it was not relevant due to the fact that native settlements were underrepresented in our region.

Comparisons between the following genotype frequencies ( $E^{*} 01: 01 / 01: 01 ; E^{*} 01: 01 / 01: 03 ; E^{*} 01: 03 / 01: 03$ ) obtained in our sample with data reported in the literature [18] were significantly different only when the Chinese population was considered (Table 2). This result is widely expected due to the fact that the Chinese did not participate in the ethnic formation of the Brazilian nation.

Our frequencies were statistically similar to those found in African Americans and Caribbeans. Significant differences were observed between our sample and results reported in the literature for
Chinese and other Ameridian populations. Through the calculation of the Fst it was possible to conclude that the Afro-descendants from Paraná are genetically more similar to Euro-Caucasians when compared to Afro-Americans. These data may reflect the different African origins between our Afro-descendants, who arrived to Brazil as slaves, brought by our Portuguese colonizers and AfroAmericans. The latter can have their origins traced to what is today Senegal and Gambia whereas Afro-Brazilians came mostly from Nigeria, Benin, Angola and Mozambique [22]. It is very well established and known that the African continent is multiethnic with very different populations from the genetic as well as from the cultural point of view. Our Southern Brazilian population has an important European contribution, of approximately 80\%, and this component is nowadays seen also in our Afro-descendants [23].

In conclusion, this is the first study regarding HLA-E polymorphisms in a Southern Brazilian urban population composed of self-reported Afro-descendants performed at such refined resolution level. Our results reflect our ethnic history, composition and evolution. Results obtained with the different selective neutrality tests were not significant and further studies would be interesting to confirm results obtained by Veiga-Castelli et al. [20] regarding the different selective pressures that may be acting in the different exons and intronic regions. 


\section{Acknowledgements}

This study was supported by the LIGH-FUNPAR Alliance Research Fund. We are very grateful to the volunteer bone marrow donors for generously accorded to provide samples for this study. We also thank LIGH staff for technical support.

\section{References}

[1] Geraghty DE. Structure of the HLA class I region and expression of its resident genes. Curr Opin Immunol 1993;5:3-7.

[2] Wei XH, Orr HT. Differential expression of HLA-E, HLA-F, and HLA-G transcripts in human tissue. Hum Immunol 1990;29:131-42.

[3] Koller BH, Geraghty DE, Shimizu Y, DeMars R, Orr HT. HLA-E. A novel HLA class I gene expressed in resting T lymphocytes. J Immunol 1988;141:897-904.

[4] Trowsdale J. Genomic structure and function in the MHC. Trends Genet 1993;9:117-22.

[5] Carosella ED, Paul P, Moreau P, Rouas-Freiss N. HLA-G and HLA-E: fundamental and pathophysiological aspects. Immunol Today 2000;21:532-4.

[6] Robinson J, Mistry K, McWilliam H, Lopez R, Parham P, Marsh SG. The IMGT/ HLA database. Nucl Acids Res 2011;39:1171-6.

[7] Matte C, Lacaille J, Zijenah L, Ward B, Roger M. HLA-G and HLA-E polymorphisms in an indigenous African population the ZVITAMBO Study Group. Hum Immunol 2000;61:1150-6.

[8] Strong RK, Holmes MA, Li P, Braun L, Lee N, Geraghty DE. HLA-E allelic variants. Correlating differential expression, peptide affinities, crystal structures, and thermal stabilities. J Biol Chem 2003;278:5082-90.

[9] Paquay MM, Schellekens J, Tilanus MG. A high-throughput Taqman approach for the discrimination of HLA-E alleles. Tissue Antigens 2009;74:514-9.

[10] Sullivan LC, Clements CS, Rossjohn J, Brooks AG. The major histocompatibility complex class Ib molecule HLA-E at the interface between innate and adaptive immunity. Tissue Antigens 2008;72:415-24.

[11] Coupel S, Moreau A, Hamidou M, Horejsi V, Soulillou JP, Charreau B. Expression and release of soluble HLA-E is an immunoregulatory feature of endothelial cell activation. Blood 2007;109:2806-14.
[12] Tomasec P, Braud VM, Rickards C, Powell MB, McSharry BP, Gadola S, et al. Surface expression of HLA-E, an inhibitor of natural killer cells, enhanced by human cytomegalovirus gpUL40. Science 2000;287:1031.

[13] Braud VM, Allan DS, O'Callaghan CA, Soderstrom K, D'Andrea A, Ogg GS, et al. HLA-E binds to natural killer cell receptors CD94/NKG2A B and C. Nature 1998;391:795-9.

[14] Miller JD, Weber DA, Ibegbu C, Pohl J, Altman JD, Jensen PE. Analysis of HLA-E peptide-binding specificity and contact residues in bound peptide required for recognition by CD94/NKG2. J Immunol 2003;171:1369-75.

[15] O'Callaghan CA. Natural killer cell surveillance of intracellular antigen processing pathways mediated by recognition of HLA-E and Qa-1b by CD94/ NKG2 receptors. Microbes Infect 2000;2:371-80.

[16] Excoffier L, Laval G, Schneider S. Arlequin (version 3.0): an integrated software package for population genetics data analysis. Evol Bioinform Online 2005; $1: 47-50$.

[17] Antoun A, Jobson S, Cook M, Moss P, Briggs D. Ethnic variability in human leukocyte antigen-E haplotypes. Tissue Antigens 2009;73:39-45.

[18] Grimsley C, Ober C. Population genetic studies of HLA-E: evidence for selection. Hum Immunol 1997;52:33-40.

[19] Steffensen R, Christiansen OB, Bennett EP, Jersild C. HLA-E polymorphism in patients with recurrent spontaneous abortion. Tissue Antigens 1998; 52:569-72.

[20] Veiga-Castelli LC, Castelli EC, Mendes Jr CT, da Silva Jr WA, Faucher MC Beauchemin K. Non-classical HLA-E gene variability in Brazilians: a nearly invariable locus surrounded by the most variable genes in the human genome. Tissue Antigens 2012;79:15-24

[21] Arnaiz-Villena A, Vargas-Alarcon G, Serrano-Vela JI, Reguera R, Martinez-Laso J, Silvera-Redondo C, et al. HLA-E polymorphism in Amerindians from Mexico (Mazatecans), Colombia (Wayu) and Chile (Mapuches): evolution of MHC-E gene. Tissue Antigens 2007;69(Suppl. 1):132-5.

[22] Gates H. Prefatory notes on the African slave trade. In: Search of our roots, how 19 extraordinary African Americans reclaimed their past. New York: Crown; 2009. p. 15-21.

[23] Lins TC, Vieira RG, Abreu BS, Grattapaglia D, Pereira RW. Genetic composition of Brazilian population samples based on a set of 28 ancestry informative SNPs. Am J Hum Biol 2010;22:187-92. 